REVISTA DE CIENCIAS FORENSES DE HONDURAS
Revista de Ciencias Forenses de Honduras ISSN: 2412-8058

ISSN: 2413-1067

revistacienciasforenseshnd@gmail.com

Dirección de Medicina Forense de Honduras Honduras

Pineda Montalvan, Darwin

Pericarditis aguda supurada

Revista de Ciencias Forenses de Honduras, vol. 4, núm. 1, 2018, Enero-Junio, p. 9

Dirección de Medicina Forense de Honduras

Honduras

Número completo

Más información del artículo

Página de la revista en redalyc.org 


\section{Pericarditis aguda supurada}

\section{Acute suppurative pericarditis}

Darwin Pineda Montalvan ${ }^{1}$

${ }^{1}$ Departamento de Patología Forense, Dirección de Medicina Forense y Universidad Nacional Autonoma de Honduras.

Correspondencia a daalpm@hotmail.com

RECIBIDO: Octubre 2018

ACEPTADO: Octubre 2018

REFERENCIA: Pineda-Montalvan D. Pericarditis aguda supurada Rev. Cienc. Forenses Honduras. 2018; 4(1):9.

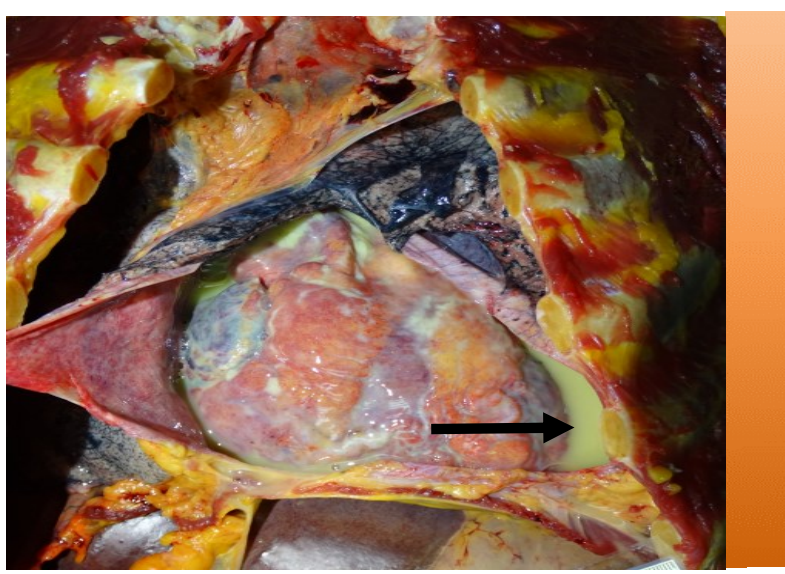

Fotografía 1. Secreción purulenta, flecha inserta.

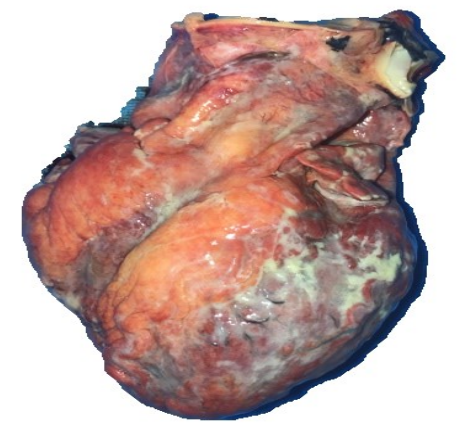

Fotografía 2. Corazón con secreción purulenta en pericardio.

Masculino, 74 años de edad, con historia de fiebre, tos, disnea y mal estado general, de 15 días de evolución, postrado, hasta que fallece, estando solo en su casa de habitación, por lo que es remitido a autopsia médico-legal. El hallazgo principal de la autopsia fue en cavidad pericárdica encontrando: a) Abundante secreción purulenta de aproximadamente $450 \mathrm{ml}$. (Fotografía 1) y b) corazón, con presencia de material blanquecino en pared del pericardio (Fotografía 2). Los pulmones se observaron con secreción purulenta y adherencias. El reporte histopatológico reportó pericarditis aguda supurada (Causa inmediata de muerte), bronquitis aguda supurada y hemorragia pulmonar.

La pericarditis aguda es la forma más común de enfermedad pericárdica, en su mayoría es de origen virall $^{1}$; siendo la pericarditis aguda supurada menos frecuente observándose secundaria a un foco infeccioso extra cardíaco ${ }^{2}$. Rey y colaboradores reportaron asociación entre un episodio reciente (menor de un mes) de infección del tracto respiratorio superior o gastrointestinal y pericarditis $(O R=37.18, I C$ $95 \%=1.91$ a $724.98, p=0.017)^{3}$.

1.- Fancello, Laura et al. "Comunidades virales asociadas con los fluidos pericárdicos humanos en la pericarditis idiopática". Ed. Krzysztof Pyrc.PLoS ONE9.4 (2014): e93367.PMC.Web.1 de octubre de 2018.

2.- Ruso L y col. Pericarditis supurada y estallido pericárdico: Doble complicación excepcional en un politraumatizado grave. Rev. Méd. Urug. [Internet]. 2002 Sep. [citado 2018 Oct 10]; 18(2):180-184. Disponible en: http://www.scielo.edu.uy/scielo.php?script=sci_arttext\&pid=\$1688-03902002000200010\&lng=es.

3.- Rey, Florian et al. "¿La pericarditis idiopática aguda está asociada con infección reciente del tracto respiratorio superior o gastroenteritis? Un estudio de casos y controles. " BMJ Open 5.11 (2015): e009141. PMC. Web. 1 de octubre de 2018. 